\title{
Mechanisms and Control of Protein Translation in the Kidney
}

\author{
Valerie Schaeffer ${ }^{b, c}$ Christine K. Abrass ${ }^{a, c, d}$ \\ a Primary and Specialty Care Medicine, and ${ }^{\mathrm{b}}$ Research and Development Service, Department of Veterans Affairs \\ Puget Sound Health Care System, ' Division of Gerontology and Geriatric Medicine, Department of Medicine, \\ University of Washington School of Medicine, and ${ }^{\mathrm{d}}$ Allergy and Inflammation Program, UW Medicine Lake Union, \\ Seattle, Wash., USA
}

\section{Key Words}

Protein synthesis $\cdot$ Translational control $\cdot \mathrm{mTOR} \cdot$ MicroRNA $\cdot$ Nephropathy $\cdot$ Diabetic nephropathy $\cdot$ Renal cancer $\cdot$

Polycystic kidney disease $\cdot$ Nephritis

\begin{abstract}
Translational control of protein synthesis is critical for cell division, homeostasis and survival. Recent data indicate that dysregulation of protein synthesis that leads to either increased or decreased expression of specific proteins contributes to the manifestations of various kidney diseases. Most of the control of protein synthesis occurs in the first or initiation phase, which is also the most complicated. Following the initiation phase is the elongation phase where the peptide chain is formed. RNA transcripts are released from ribosomes after the termination phase. Transcripts can be translated in a cap-dependent or cap-independent manner. The mTOR (mammalian target of rapamycin) cascade regulates translation of most cap-dependent transcripts at the level of initiation and elongation, which represents $95 \%$ of total transcripts. During specific events (e.g. mitosis, stress cell survival) control of the less-common cap-independent transcripts occurs which allows the cell to adapt to the new state. Activation of stress kinases and inactivation of the mTOR pathway are at the center of this adaptive mechanism. Recent studies have elucidated the role of micro-RNAs (miRs)
\end{abstract}

in controlling translation. miRs bind directly to specific transcripts and most often directly reduce translation; however, by targeting other positive or negative regulators of the pathways regulating protein synthesis they may indirectly affect synthetic levels of other transcripts. Several examples are described below in which these mechanisms are intertwined and act together to dysregulate protein synthesis in the diseased kidney.

Copyright $\odot 2009$ S. Karger AG, Basel

\section{Introduction}

During the last decade, sequencing of the human genome has focused research efforts on understanding mechanisms that control gene transcription. As these approaches have grown in sophistication and whole transcriptomes have been correlated with protein levels, it has become apparent that translational control also plays a critical role in determining the final proteome. After production of a mature mRNA, several critical steps control the amount of protein that is made. Control of protein translation has emerged as an important aspect in cell homeostasis and survival, and is critically important to the expression of about $25 \%$ of proteins expressed by individual cells. Translation of mRNA into protein is primarily regulated at the initiation phase where mecha-

\section{KARGER \\ Fax +41 613061234 E-Mail karger@karger.ch} www.karger.com
() 2009 S. Karger AG, Basel 0250-8095/10/0313-0189\$26.00/0

Accessible online at:

www.karger.com/ajn
Prof. Christine K. Abrass, MD

UW Medicine Lake Union

815 Mercer Street

Seattle, WA 98109 (USA)

Tel. +1 206897 1966, Fax +1 206897 1300, E-Mail cabrass@u.washington.edu 


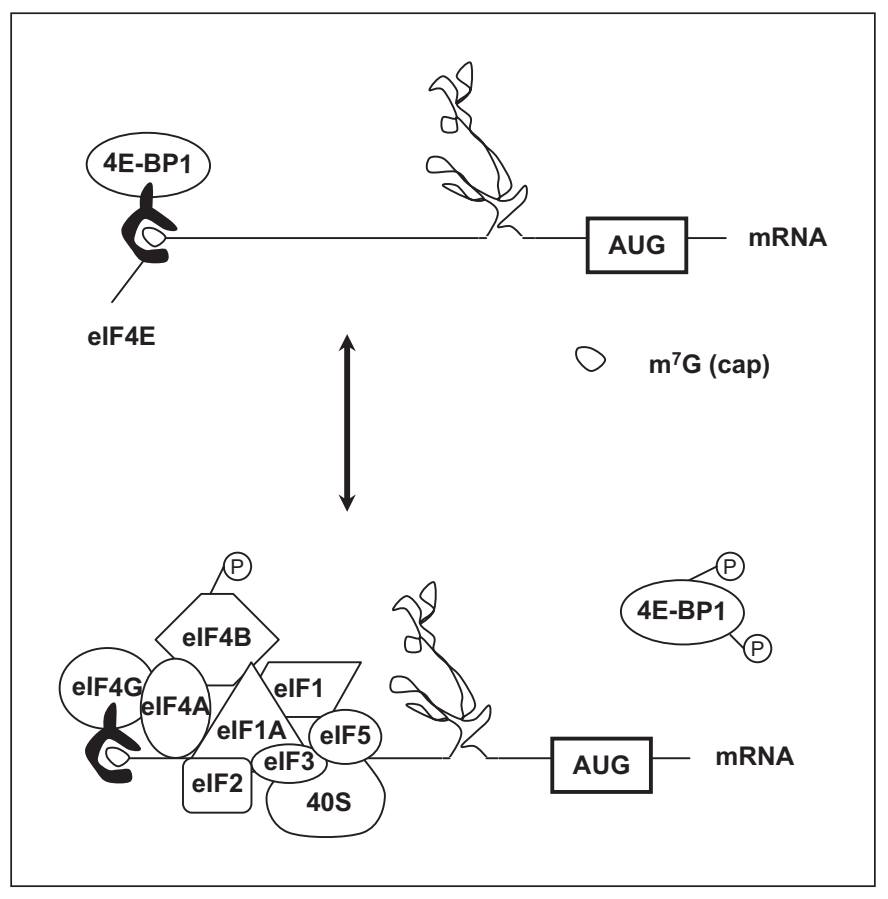

Fig. 1. Hypophosphorylated 4E-BP1 has a strong affinity for eIF4E, the cap-binding factor, and prevents its interaction with eIF4G and the recruitment of the other eIFs, thus inhibiting translation initiation. In response to intra- or extracellular stimuli, 4E-BP1 is phosphorylated by mTOR and frees eIF4E, which promotes the formation of the eIF4F complex (composed of eIF4E, $4 \mathrm{G}$ and $4 \mathrm{~A}$ ) and translation initiation.

nisms are in place to ensure that changes are implemented rapidly in response to stimuli. In particular, general cap-dependent translation, which concerns about $95 \%$ of the transcripts, is often inhibited in cases of stress, whereas cap-independent transcript translation is increased, producing specific proteins needed for the cell survival. In addition, this process allows the cell to conserve energy. Other levels of control, including micro-RNAs (miRs) and stress-kinase activation, converge to modulate the final amount and composition of proteins that are synthesized $[1,2]$. These different systems can work together to arrest translation in case of acute stressors, or become dysregulated in the presence of persistent stressors and thereby contribute to disease. In each case, the composition of the proteome is changed with functional consequences. The complex series of control points provides fine-tuning that is necessary for appropriate cell function, but this also provides many points at which disease-associated alterations can impact protein expression and influence disease pathogenesis. The final proteome also takes in account changes in degradation processes. This review will summarize what is currently known about mechanisms of control of protein translation, and describe examples in which alterations in these pathways are relevant to kidney diseases.

\section{General Mechanism of Translation}

Gene expression starts with production of a RNA transcript from a DNA template and its processing in the nucleus followed by translation of mature mRNA in the cytosol into a functional protein product. Although the composition of the transcriptome is controlled by transcription, ultimately protein composition is defined by the rate of translation. Traditionally, translation is divided into three steps: initiation, elongation and termination, with translation initiation often being the limiting step.

\section{Initiation Phase}

About $95 \%$ of total cellular mRNAs are translated in a cap-dependent fashion where the $40 \mathrm{~S}$ ribosome subunit is recruited to the canonical $\mathrm{m}^{7} \mathrm{GpppN}$ (7-methyl guanosine) cap at the $5^{\prime}$ end of the mRNA with the pre-initiation complex (PIC). In addition to the $40 \mathrm{~S}$ ribosomal subunit, the PIC is composed of several eukaryotic initiation factors (eIFs), including eIF1, eIF1A, eIF2, the methionyl initiator tRNA, eIF3, eIF5 and the cap-binding factor, eIF4E, and GTP (guanosine-5'-triphosphate) (fig. 1) [3]. Once the PIC is assembled, it migrating linearly along the RNA from $5^{\prime}$ to $3^{\prime}$ until it recognizes the initiation codon (AUG). After recognition, hydrolysis of the GTP bound to eIF2 is triggered, as is the release of eIF2-GDP (guanosine-5'-diphosphate). The large $60 \mathrm{~S}$ ribosomal subunit is then recruited to form the $80 \mathrm{~S}$ ribosome, and protein synthesis proceeds to the elongation phase. Recycling of the eIF2-GDP into functional eIF2-GTP is done by eIF2B, a pentameric guanine exchange factor, which is the subject of important regulation by stress kinase as discussed below.

\section{Elongation Phase}

To elongate the polypeptide chain, amino-acyl tRNAs are brought to the ribosome by pairing the anti-codon of the tRNA with the codon of the mRNA. Several eukaryotic elongation factors (eEFs) are responsible for the execution of this phase. eEF1A and eEF1B are involved in recruitment of amino acyl-tRNAs to the ribosome. eEF2 affects translocation of the ribosome along the RNA after 
the peptide bond between adjacent amino acids has formed. The rate of the elongation phase is controlled through eEF2, which can be phosphorylated and inactivated by eEF2K (eEF2 kinase). The eEF2K is itself under the control of the signal-dependent mammalian target of rapamycin (mTOR) pathway (fig. 4).

\section{Termination Phase}

Three eukaryotic release factors (eRFs) facilitate the release of the peptide chain and the $40 \mathrm{~S}$ and $60 \mathrm{~S}$ subunits of the ribosome, after the complex encounters the stop codon. Release of the mRNA-bound ribosomes is important as ribosome recycling is a crucial process required to initiate new rounds of translation. This process is highly controlled as reformation of the $80 \mathrm{~S}$ ribosome is prevented by the eukaryotic initiation factor 6 (eIF6) factor. The eIF6 was initially shown to be a link between extracellular stimuli and the activity of the $60 \mathrm{~S}$ ribosomal subunit. It associates with the $60 \mathrm{~S}$ ribosome to prevent its binding to the $40 \mathrm{~S}$ subunit and blocks translation initiation [4]. Other important functions of eIF6 in translation control have since emerged such as $\mathrm{miR}$ silencing through the RNA-induced silencing complex (RISC), which depends on the presence of eIF6 [5].

\section{General Control of Translation}

Translation is a highly regulated process, allowing the cell to respond promptly to environmental changes. Control of translation is achieved at several levels through mechanisms that affect either specific mRNAs (i.e. mRNAs with specific features/sequences) or all mRNAs at once (nonspecific control). The specificity of a transcript generally depends on its 5'UTR (untranslated region) and 3'UTR. Features (sequence as well as structure) within the 5'UTR of a transcript determine if it will be translated by a cap-dependent or -independent mechanisms (see below) while the specific miR-binding sites within the 3'UTR of a transcript can block its translation if the corresponding miRs are expressed. Alternatively, the same pathway/molecule can act on specific mRNAs and on general translation by different mechanisms (mixed control). As an example, the mTOR pathway acts specifically on promoting cap-dependent translation and elongation when activated. Finally, several specific mechanisms of control can interact, such as miR and cap-dependent translation, to control and fine-tune the composition of the proteome.

Translational Control in the Kidney

\section{Cap-Dependent Translation}

The efficiency of cap-dependent translation is influenced by the complexity of the $5^{\prime} \mathrm{UTR}$, as the scanning model predicts that long, GC-rich, highly structured 5'UTRs prevent efficient translation. Scanning efficiency is greatly influenced by the negative free energy (stability) of the hairpins and their position relative to the $5^{\prime}$ cap [6]. Cap-dependent mRNAs with uncomplicated UTRs are easily translated because not much energy is required to unwind the 5'UTR and ribosomes freely scan the RNA to find the starting codon. Among the transcripts translated through the cap-dependent mechanism, only about $10 \%$ of them have unusually complicated 5'UTRs [7]. For these, activity of ATP-dependent helicases is needed for unwinding these inhibitory secondary structures. Translation initiation of complex and highly structured mRNAs can be controlled by a signal-dependent cascade, the mTOR pathway. In addition, the MAPK (mitogen-activated protein kinase) ERK (extracellular signal-regulated kinase) can also regulate the phosphorylation of 4E-BP1 [8] and appears to be downstream of PI3K [9].

\section{Cap-Independent Translation}

About 3\% of cellular mRNAs have features in their $5^{\prime}$ UTRs that allow assembly of the translation initiation machinery near or at the start codon, abolishing the need for formation of a cap-dependent initiation complex and scanning [10]. These features, called internal ribosome entry sites (IRESs), have no similarity in primary or secondary structures; yet, they allow initiation directly at the start codon. Besides the cap-dependent and IRESmediated translation initiation, a very small number $(0.1$ to $1 \%)$ of mRNAs are translated via re-initiation. These mRNAs contain one or several upstream open reading frames (ORFs, uORFs), which usually do not generate a functional product. For the main ORF to be translated, it must survive the first termination event in order to be reinitiated (for review, see [11, 12]). In response to cellular stress, cap-dependent translation is often shut-down and cap-independent translation, IRES and uORF, is increased allowing the cell to survive (for reviews, see [1316]).

\section{Activation of Stress Kinases and the Switch from}

Cap-Dependent to Cap-Independent Translation

Many cell stressors (e.g. heat, viral infection, nutrient limitations, endoplasmic reticulum (ER) stress, ultraviolet radiation) shut down protein synthesis by activating one of the eIF2 kinases (eIF2K), which phosphorylates eIF2, and blocks the guanine-exchange factor eIF2B

Am J Nephrol 2010;31:189-201 


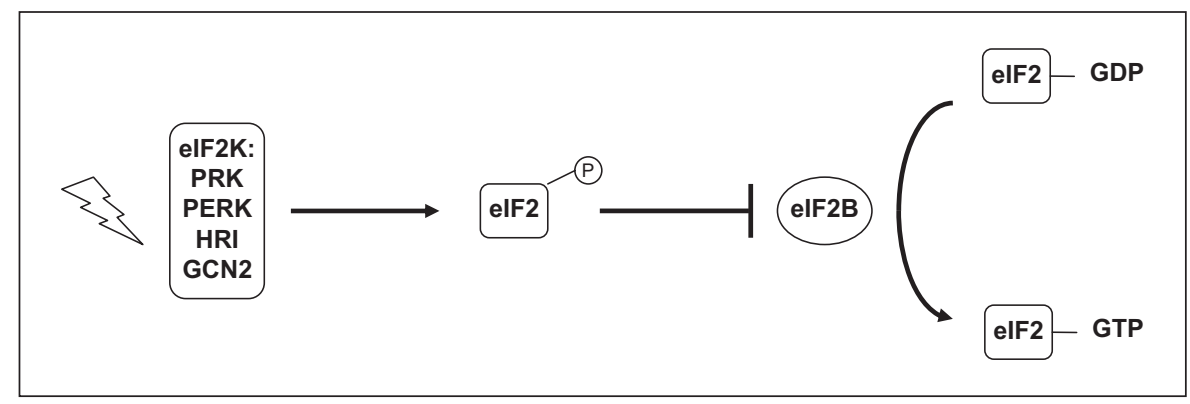

Fig. 2. Four kinases belong to the eIF2K family: (1) protein kinase $\mathrm{R}$ (PKR), a kinase activated by heat, viral infection and ultraviolet irradiation; (2) PKR-like ER kinase (PERK), a resident of the ER that is triggered by the accumulation of unfolded proteins; (3) heme-regulated initiation factor 2 a kinase (HRI), which controls the balance of synthesis of globin chains and heme during eryth- rocyte maturation and senses oxidative stress produced by arsenite, and (4) general control nonderepressible-2 (GCN2), which is susceptible to amino-acid deprivation. eIF2K phosphorylates eIF2 with then becomes an inhibitor rather than a substrate of the guanine nucleotide exchange factor eIF2B.

tion (fig. 4). Studies in Drosophila, Caenorhabditis elegans, and mammalian cells suggest that tightly controlled processes such as mitosis or resistance to oxidative, osmotic, hypoxic and apoptotic stresses all involve downregulation of the mTOR cascade [18-21]. When global protein synthesis is shut-down, specific cap-independent mRNAs are translated that are critical to the adaptive cellular response. In several disease states, over-activation of the mTOR pathway has been demonstrated, leading to physiological imbalance and higher than normal protein synthesis. While overactivation of mTOR activity would affect primarily mRNAs with a complicated $5^{\prime}$ UTR through activation of the RNA helicase eIF4A and eIF4E (fig. 4), general translation would also benefit through activation of the elongation factor eEF2 and 5'TOP mRNAs. In contrast, down-regulation of the mTOR cascade inhibits primarily the cap-dependent translation, whereas mRNAs with an IRES or uncomplicated 5'UTRs are still expressed [22].

\section{Micro-RNA-Regulated Translation}

Translation can also be regulated at the 3'UTR side of mRNAs by miRs, which are non-coding, single-stranded RNA molecules ranging from 18 to 27 nucleotides in length that bind to specific sequences in the mRNA. It is predicted that about $30 \%$ of human genes are regulated by miRs, which can target specific mRNAs for translational repression by inhibiting the early steps of initiation $[23,24]$. miRs have also been implicated in the cellular stress response and often, stress-induced reprogramming of translation up-regulates transcription of miRs, which have been called 'safeguards against turmoil' [1, 16]. The nascent transcripts are processed into mature 


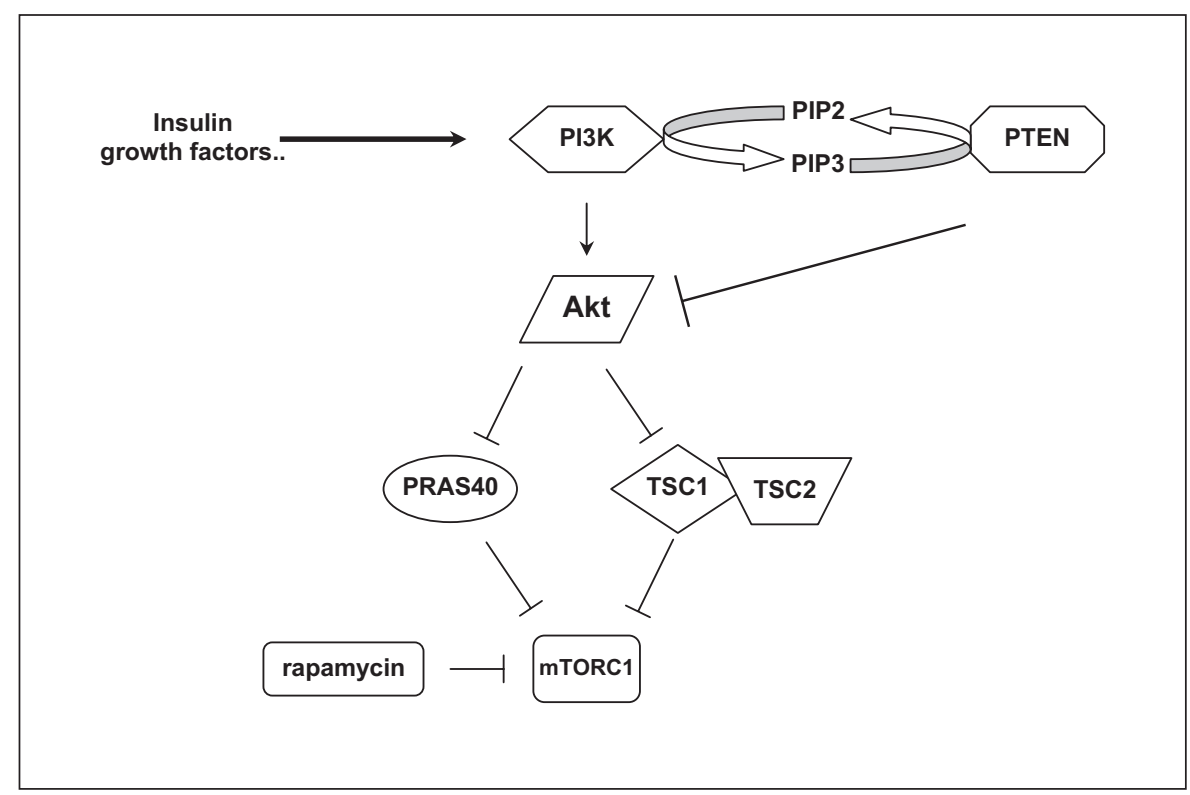

Fig. 3. Activation of PI3K by extracellular signals leads to the production of the lipid second messenger phosphatidylinositol-3,4,5triphosphate (PIP3) from phosphatidylinositol 4,5-bisphosphate (PIP2) in the membrane. Among other things, PIP3 translocates Akt to the membrane where it becomes phosphorylated in its activation loop at Thr 308. Activated Akt is able to release mTOR inhibition by phosphorylating the endogenous mTORC1 inhibitor, proline-rich Akt substrate 40 (PRAS40) [103], and by phosphorylation of tuberous sclerosis protein TSC2 (tuberin), which is in an inhibitory complex with TSC1 (hamartin). The mTOR sig- naling network consists of two major complexes, mTORC1, which regulates protein synthesis, cell growth and autophagy, and mTORC2 (not pictured), which regulates cytoskeletal organization. The mTORC1 complex is rapamycin-sensitive while mTORC2 is only rapamycin-sensitive after prolonged exposure [104]. After activation, mTORC2 is able to phosphorylate Akt on Ser 473 (for reviews, see $[105,106]$ ). The PTEN (phosphatase and tensin homolog deleted on chromosome ten) tumor suppressor protein regulates PI3K signaling by dephosphorylating the lipid signaling intermediate PIP3 [107].
Fig. 4. Activated PI3K signaling or activated p70S6 kinase [108] phosphorylate the mTOR kinase, which then activates p70S6 kinase. In turn, this phosphorylates and activates eIF4B, which stimulates the helicase activity of the eIF4A, the helicase that unwinds inhibitory secondary structures in the 5'UTR of mRNAs. Phosphorylation of the p70S6K has three additional effects. First, phosphorylation of the ribosomal protein $\mathrm{rpS6}$, a component of the $40 \mathrm{~S}$ ribosome. In addition, although this issue is controversial $[109,110]$, p70S6K is thought to control the translation of mRNAs containing oligopyrimidime tracts in their $5^{\prime}$ UTR (5' TOP), mostly mRNAs encoding for components of the translation machinery. Second, phosphorylation of the eukaryotic elongation factor 2 kinase $(\mathrm{eEF} 2 \mathrm{~K})$ stimulates the translation elongation phase (for reviews, see $[105,107,111,112])$. Third, the tumor suppressor programmed cell death 4 (PDCD4), which also regulates eIF4A activity, is a target of the mTOR pathway via the p70S6K. PDCD4 is able to bind the eIF4A helicase and block the translation of mRNAs with highly structured $5^{\prime}$ UTRs, while phosphorylated PDCD4 is rapidly degraded by ubiquitination and the eIF4A helicase is released [113]. As mentioned in figure 1, in response to mTOR activation, 4E-BP1 is phosphorylated and frees eIF4E, which promotes translation initiation.

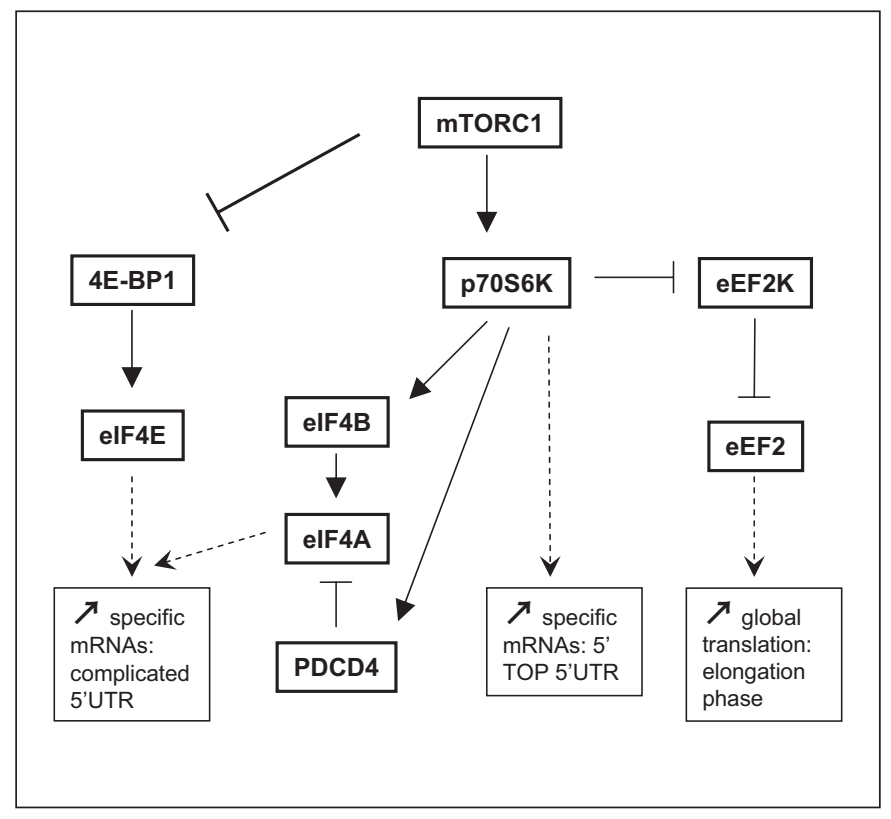

Am J Nephrol 2010;31:189-201 
miRs in a two-step process by the RNAse enzymes, Drosha and Dicer, into pre-miRs, and then into the mature miRs. miRs bind to specific sequences, generally in the 3'UTR of target mRNA, via their conserved seed sequence. Mature miRs and argonaute (AGO) proteins then associate into the RNA interference effector complex (RISC) and target-specific mRNAs either for translational repression or for degradation depending on the complementarity of the seed sequence [25]. Translation repression by miR likely blocks the initiation step [23]. Alternatively, a postinitiation mechanism may also contribute, as miR-repressed constructs are associated with heavy microribonucleoproteins that co-sediment with polysomes [26]. These mechanisms and their implications for translation are discussed in detail elsewhere [27]. Repressed mRNA-miR complexes become localized in stress granules, which are the sites where stalled mRNA-polysome complexes accumulate when translation initiation is inhibited $[1,17]$. Stress granules assemble upon phosphorylation of eIF2 by one of the stress kinases (eIF2K); yet, they are able to dissemble rapidly in response to changing conditions [1]. Several factors, such as SMAD, lin-28 and hnRNPA1 (heterogeneous nuclear ribonucleoprotein $\mathrm{A} 1$ ), alter the processing of the nascent $\mathrm{miR}$ transcripts, and therefore have an indirect effect on translation [28].

Finally these key pathways and proteins allow for tight control of the responses to acute and chronic perturbants that result in a change in the cell phenotype and function through changes in the global amount of protein that is produced. As the condition surrounding the cells changes, protein synthesis is modified in response and often a switch from cap-dependent to cap-independent translation accompanies a change in miR expression which further fine-tunes the composition of the proteome. Specific examples of complex control of protein translation as they relate to the kidney are discussed below.

\section{Effects of Translation on Kidney Function and Diseases}

The kidney is a highly metabolically active organ, subject to oxidative stress, exposure to a variety of toxins, and physiological needs that require changes in patterns and rates of protein synthesis. Stressors are known to halt general cap-dependent protein synthesis, in order to conserve energy and allow the cell to survive, as well as to increase cap-independent translation of protein crucial to the survival mechanism. Stress kinases play an impor- tant role in kidney diseases. When activated, they impair general protein production while allowing only specific proteins to be made. They also trigger formation of the stress granules where upregulated miRs and their stalled target mRNAs are stored, depleting the kidney of critically important proteins.

\section{Diabetic Nephropathy}

Diabetic nephropathy (DN), a major cause of endstage kidney disease, is characterized by glomerular basement membrane (GBM) thickening and mesangial matrix expansion, which leads to glomerulosclerosis, tubulointerstitial fibrosis and loss of kidney function. In some cases, enhanced gene transcription correlates with the increase in a specific protein, but in other cases there is a disassociation between mRNA and protein levels. Recognition of this disassociation has prompted evaluation of the role of control of protein translation in both the change in amount and composition of proteins in the kidney in diabetes [29-33]. Several mechanisms controlling protein synthesis are intricately implicated in the different phases that accompany the evolution of DN. After a certain stress threshold is achieved, there is a switch from cap-dependent to cap-independent translation as the mTOR cascade is downregulated and the stress kinases are up-regulated. Proteins important for survival are still translated, but other proteins that are critical for kidney function might be missing. This shift from capdependent to cap-independent translation happens at about 30 days after diabetes induction in the rat kidney, and is likely due to upregulation of oxidative [34] and endoplasmic reticulum (ER) stress $[35,36]$, both of which are implicated in the pathogenesis of DN. miRs are also upregulated, adding to the dysregulation of the pathway controlling translation (mTOR) or downregulating crucial proteins for kidney function.

Cap-Dependent and Cap-Independent Mechanisms in DN

In the rat kidney, the first month following diabetes induction is characterized by renal hypertrophy, which correlates with glucose-mediated increases in activation of the mTOR pathway and increases in cap-dependent protein synthesis. The early phase can be attenuated by treatment with rapamycin, a specific inhibitor of mTOR. When rapamycin treatment is started as early as 2 days after induction of diabetes by streptozotocin (STZ), mTOR activation is blocked and glomerular and wholekidney hypertrophy are prevented despite continued hyperglycemia $[37,38]$. This suggests that mTOR pathway 
activation is involved in the early initiation of DN. These findings contrast with the observation that mTOR kinase activity is reduced after 4 weeks of hyperglycemia [39], suggesting that persistent exposure to oxidative [34] and ER stresses might induce compensatory responses [35, 36] that downregulate cap-dependent protein synthesis [14]. After 30 days, there is a switch between downregulation of cap-dependent translation and upregulation of translation by cap-independent mechanisms, as transcripts that contain UORFs and IRES in their $5^{\prime}$ UTR are actively translated [40-42]. This leads to a shift in the composition of the proteins that are over-expressed. For example, hyperglycemia is known to upregulate fibroblast growth factor-2, which bears an IRES in its $5^{\prime} \mathrm{UTR}$ $[40,41,43,44]$. Similarly, high glucose leads to translation of $\mathrm{CD} 36$, a scavenger receptor that mediates uptake of oxidized low-density lipoprotein, via ribosome re-initiation $[42,45]$. Whether CD36 re-initiation is regulated via eIF2 or not is not known [46]. Among the ECM (extracellular matrix) proteins increased in $\mathrm{DN}$, laminin- $\beta 1$ (lamb1) $[47,48]$ translation is stimulated by hyperglycemia by an IRES-driven mechanism [49].

In animal models of type 2 diabetes ( $\mathrm{db} / \mathrm{db}$ mice, with hyperglycemia and hyperinsulinemia) or in STZ-induced diabetic animals treated with insulin, the mTOR pathway is activated, as insulin is a potent activator of the mTOR cascade [50]. This activation is most likely to occur on the top of the changes described above (activation of the capindependent translation) as oxidative and ER stresses are still present in DN occurring from type 2 diabetes or in STZ-induced diabetic animals treated with insulin. Longterm or late benefits of rapamycin treatment [51-53] in type 2 models or those treated with insulin are likely mediated in part by blocking these well-known effects of insulin on mTOR; however, the consequences of other factors that also stimulate mTOR would likewise be affected. As an example, high glucose and high insulin were shown to activate the mTOR cascade and phosphorylation of the eEF2 kinase to stimulate the translation elongation phase and more specifically translation of laminin- $\beta 1[31,32]$.

\section{Role of miRs in DN}

Several miRs are increased in mesangial cells and animal models of DN by chronic high-glucose treatment. Glucose-mediated up-regulation of miR-377 indirectly leads to increased fibronectin production via down-regulation of superoxide dismutases (SODs) and p21-activated kinase, which normally inhibit ECM production [54]. Moreover, the reduction of both SOD1 and SOD2 by
miR-377 enhances oxidative stress in mesangial cells [54]. Similarly, HG-mediated increases in transforming growth factor- $\beta$ (TGF $\beta$ ) leads to upregulation of miR192 , which indirectly increases collagen via inhibition of an E-box repressor [55]. Although to date the majority of studies of DN have focused on factors that lead to ECM accumulation by upregulation of miRs $[54,55]$, reductions in critically important proteins via direct $\mathrm{miR}$ interaction may also contribute to organ dysfunction and disease progression. As such, overexpression of TGF $\beta 1$ in mice upregulated miR-23b, which directly reduced the expression of podocyte proteins, WT1 (Wilms tumor 1), nephrin and podocin, that are important to normal function of the filtration barrier [28]. Similarly, 5-6 weeks after diabetes induction, the laminin- $\beta 2$ (lamb2) protein, a heterotrimeric matrix glycoprotein, which is a critical component of the GBM, is greatly reduced [56], at a time when the mTOR pathway is thought to be inactive if no insulin is present [39]. As the lamb2 3'UTR has a putative miR-377 binding site, glucose-mediated increases in expression of miR-377, as shown by [54], could be responsible for the reduction in laminin- $\beta 2$ translation in vitro [57]. Given that loss of laminin- $\beta 2$, either in null-mutant mice or humans with Pierson's syndrome [58-61] results in significant proteinuria, reductions in critically important proteins such as laminin- $\beta 2$ via translational regulation might contribute to the development of proteinuria in diabetic nephropathy [62].

Recently, in animals with type 2 diabetes, miRs have been implicated in a mechanism that can mediate prolonged activation of the mTOR pathway. Kato et al. [55, $63,64]$ demonstrated that miR-192, which inhibits translation of an E-box repressor, mediates the transcriptional upregulation, not only of collagen as discussed earlier, but also of miR-216a and miR-217. The same group also elegantly demonstrated in mesangial cells in vitro and in $\mathrm{DN}$ in vivo that high glucose-associated TGF $\beta$-stimulated production of miR-216a and miR-217 inhibited the translation of PTEN (phosphatase and tensin homologue) [64]. In turn, loss of PTEN results in the constant activation of Akt [64] and therefore drives activation of the mTOR cascade. This results in persistent increases in protein synthesis in the kidney and leads to a change in the composition of the proteome. This suggests that the same miRs are likely to be regulated and contributing to similar changes in DN in both DM1 and DM2.

It is likely that the next crucial steps in understanding the mechanisms underlying increases and decreases in expression of critical proteins in the diabetic kidney will involve direct regulation by miRs. Alterations in both 
glucose and insulin levels can impact cap-dependent, as well as cap-independent translation, alter mTOR cascade activity and modulate miRs. Depending on the pathways that are affected and the specific mechanisms involved, alterations in regulation of translation of individual mRNAs will lead to a change in both the amount and composition of proteins expressed in the kidney [65-68]. This will have important implications for understanding the pathogenesis of $\mathrm{DN}$.

\section{Renal Cancer}

Cancer arises from defects in control of cell proliferation. During normal mitosis, protein synthesis is tightly regulated through a switch from cap-dependent to capindependent (IRES-mediated) translation, which is required for controlled cell division [69]. This switch depends on downregulation of the mTOR pathway, as well as inhibition of a target of mTOR, eIF4B, by a mTOR-independent mechanism [69]. Contrary to DN, the mTOR cascade is permanently hyperactivated in renal cell cancer (RCC) [70]. Moreover, cancer cells acquire migratory and invasive properties as they undergo epithelial to mesenchymal transition (EMT), a process that is characterized by loss of cell-cell contacts [71]. miRs influence this process through reduced translation of E-cadherin, the protein that mediates formation of cell-cell contacts.

\section{Cap-Dependent and Cap-Independent Mechanisms} in RCC

In normal, noncancerous cells, general cap-dependent protein synthesis is halted during mitosis and several proteins, including the RNA helicase eIF4A, eIF4B and a tumor suppressor, which regulates eIF4A activity (Programmed Cell Death 4, PDCD4), participate in this crucial mechanism (fig. 4). Both eIF4B and the tumor suppressor, PDCD4, are targets of the mTOR pathway via the p70S6K (fig. 4). Phosphorylation of the tumor suppressor PDCD4 releases eIF4A from PDCD4's inhibitory grip, while phosphorylation of eIF4B stimulates the helicase activity of eIF4A. This cascade must be down-regulated to halt cap-dependent translation and for normal mitosis to occur. If the mTOR pathway is still active during mitosis, the switch form cap-dependent to cap-independent translation does not happen and cells become transformed as if eIF4E were overexpressed [72]. Additionally, in RCC, activation of mTOR [70] leads to translational upregulation of HIF- $\alpha$ (hypoxia-inducible factor alpha) and VEGF (vascular endothelial growth factor) $[73,74]$ that contribute to cancer progression by promoting angiogenesis. In RCC, as well as in a multitude of other can- cers, the mTOR pathway is hyper-activated, although the mechanisms leading to this activation in cancer are not entirely understood [70, 75].

Blockade of mTOR activation with rapamycin has shown promising results in the treatment of advanced RCC [75]. Although nanomolar concentrations of rapamycin or its analogs can reduce mTOR activity, micromolar concentrations have additional effects on phosphorylation of eEF2 and eIF 2 that decrease the elongation rate and lead to profound inhibition of global protein synthesis $[75,76]$. RCC patients that received the highest weekly dose of the rapamycin analog, CCI-779, had better survival than those in the lower dosage group [76]. Statins, which block mTOR activation by reducing $\mathrm{p} 70 \mathrm{~S} 6 \mathrm{~K}$ phosphorylation and block cap-dependent initiation of translation through up-regulation of PDCD4, have also shown promising results [77]. Both of these approaches to the treatment of RCC suggest that greater inhibition of global protein synthesis than just inhibition of transcripts directly regulated by the mTOR cascade provides added benefit in reducing cell proliferation.

Role of miRs in RCC

Changes in levels of miRs that have direct effects, as well as effects through modulation of the mTOR pathway, have been reported in RCC. In a genomewide screen, miR-141 and miR-200c were found to be down-regulated in RCC compared to normal tissues [78]. Downregulation of these miRs led to up-regulation of one of the miR141/200c targets, ZEB2 (zinc finger E-box binding homeobox 2), which normally functions as a transcriptional repressor that inhibits E-cadherin expression [78]. Loss of E-cadherin is an indicator that cells have undergone EMT, which correlates with metastatic disease and a poor prognosis in RCC $[79,80]$. E2F3, a transcription factor that regulates genes that control progression through the cell cycle, is reduced in RCC as a result of miR-34a-mediated inhibition of translation [81]. Additional effects on protein translation result from changes to mTOR pathway activation that are influenced by miR-mediated alterations in expression levels of mTOR pathway components. Up-regulation of miR-21 in RCC [78] leads to reductions in some miR-21 targets such as PTEN and PDCD4. As discussed above, loss of PTEN hyperactivates mTOR through Akt, which then stimulates protein synthesis and leads to the transformation of cells through dysregulation of mitosis. Downregulation of the tumor suppressor, PDCD4, releases the RNA helicase, eIF4A, which leads to activation of translation of mRNAs with complicated 5'UTRs. These effects alter the amount and 
composition of the proteins that are expressed by RCC cells without any need for growth factors or other upstream activators.

Alterations in several key steps in control of cell proliferation are needed for a cell to become cancerous and metastasize; however, there is growing evidence that dysregulation of translational control is a common feature in cancer, and that control is disrupted by abnormalities in mTOR pathway activation or miR-mediated regulation of specific proteins.

\section{Polycystic Kidney Disease}

Polycystic kidney disease (PKD) leads to end-stage kidney failure as a result of progressive growth of renal cysts [82, 83]. Although specific gene mutations have been identified in clinical subtypes of PDK (PKD1, PKD2, PKHD1), the mechanisms that lead to cyst formation and growth are poorly understood. Mutations in all three genes have been linked to processes that affect cell growth (cell size and protein content) and cell proliferation (dysregulation of cell division); yet, details of these mechanisms are just beginning to emerge. Similar to RCC, the mTOR cascade is hyperactivated and miR-21 has been shown to be upregulated.

Cap-Dependent and Cap-Independent Mechanisms in PKD

The polycystin-1 (PKD1) gene product is a receptorlike transmembrane protein with a large intracellular cytoplasmic tail. When polycystin-1 is mutated or inactivated in PKD patients or in animal models of PKD, mTOR pathway activity is increased in renal cysts as compared to controls [84]. It was shown that the cytoplasmic tail of PKD1 interacts with TSC2/tuberin (tuberous sclerosis complex 2, TSC2), a key negative regulator of the mTOR pathway [83] and PDK1 mutants are similar to TSC2 mutations (leading to tuberous sclerosis) which also consists of renal cysts and benign tumors in multiple organs. In a similar way, fibrocystin defects are also associated with activation of the mTOR cascade [85], although the molecular components of the fibrocystin (PKHD1) pathway are not as well defined. In a rat model of $\mathrm{PKD}$, increased activation of the mTOR pathway was treated successfully with rapamycin [86-88] as the resultant decrease in protein synthesis was accompanied by a reduction in the rate of cyst growth.

Several mechanisms other than mTOR exist to ensure that global protein synthesis is shut down during the cell cycle, including activation of the stress kinases (eIF2K). This provides a greater inhibition of global protein syn- thesis than just inhibition of the mTOR cascade. The protein polycystin-2 (PKD2) is a calcium-regulated, calcium-permeable ion channel located on the endoplasmic reticulum membrane. The wild-type polycystin- 2 ensures a slow-down of general protein synthesis by promoting eIF2 phosphorylation through PERK (PKR-like ER kinase) activation while mutations of polycystin-2 lead to uncontrolled cell proliferation [89] as PERK is not activated and protein synthesis is not inhibited.

Role of miRs in PKD

A few studies have examined the relation between miR dysregulation and PKD [90, 91], but only one related to the kidney [91]. Pandey et al. [91] found 30 dysregulated miRs in the kidneys of a rat model of PKD. Surprisingly, of 30 miRs that were differentially regulated, only miR-21 was upregulated [91]. In RCC, miR-21 was shown to target the tumor suppressors PTEN and PDCD4, and thus to enhance activation of the mTOR cascade [78]. Along with the mechanisms described above, this would enhance protein translation and cyst growth. The miRs that were reduced might similarly promote enhanced translation of their targets, as miR-mediated reductions in translation would be lost.

In summary, PKD is characterized by uncontrolled protein translation during cell division, which is a time when inhibition of global translation is usually necessary. This occurs either by inappropriate activation of the mTOR cascade by polycystin-1 or fibrocystin mutants, or by failed PERK activation by polycystin-2 mutants. Changes in $\mathrm{miR}$ are also predicted to lead to enhanced protein synthesis through both direct effects on mRNA targets (such as inhibition of PDC4), as well as indirect effects through modulation of mTOR activity (such as inhibition of PTEN). Dysregulated protein synthesis in PKD leads to cell growth and proliferation, which drive cyst expansion; thus, therapies that target control of protein translation may impact the rate of progression of these genetic disorders.

\section{Nephritis}

In immune-mediated forms of chronic nephritis, persistent activation of the inflammatory response leads to progressive fibrosis. As in other disorders, many inflammatory mediators activate the mTOR pathway and through mechanisms described above impact the composition and amount of proteins that accumulate in the kidney. 
Cap-Dependent and Cap-Independent Mechanisms in Nephritis

In inflammatory syndromes, activation of protein synthesis is a common phenomenon, and the mTOR pathway is particularly implicated in the control of cytokine production. This has been confirmed in human and mouse lupus nephritis [92], and anti-Thyl.1-induced chronic glomerulosclerosis in the rat $[93,94]$. Support for the importance of mTOR activation in the Thyl.1 model comes from studies in which inhibition of mTOR with rapamycin attenuates matrix accumulation, reduces proteinuria, and reduces cell proliferation $[93,94]$.

Despite the hyperactivation of the mTOR-dependent transcripts in several cases of nephritis (see above), several studies have shown that endogenous attenuation of protein synthesis was achieved, via activation of PERK and phosphorylation of eIF2, in several models of nephritis, as a protection mechanism [36, 95-98]. Similarly, in an in vivo model of C5b-9-induced glomerular epithelial cell injury, phosphorylation (and activation) of PERK, and eIF2, consequently, were significantly enhanced compared to control, and global protein synthesis was suppressed [96]. This ER-stress response, due to the attack by the complement, is a mechanism of defense to protect the cells and downregulate cap-dependent protein synthesis. As is often the case, when general cap-dependent translation is reduced, cap-independent translation is increased for genes that are critical to kidney function. As an example, nephrin is a critical slit diaphragm protein involved in maintaining the filtration barrier [96] and its translation is maintained through the cap-independent translation up-regulation: the nephrin $5^{\prime} \mathrm{UTR}$ mRNA, which has several uORFs, was shown to be upregulated, when the ER-stress response was activated and PERK was phosphorylated [96].

\section{Role of miRs in Nephritis}

During a normal inflammatory response, modulation of miRs leads to cytokine production, which when it becomes persistent can lead to organ damage [99]. In mice, overexpression of the miR-17-92 cluster in lymphocytes leads to a lymphoproliferative disorder and autoimmune kidney disease with enlarged glomeruli, mesangial expansion, and proteinuria [100]. IL-6, a potent mediator of renal fibrosis, can activate expression of the miR-17/92 cluster [101]. Overexpression of this cluster reduces the translation of PTEN, which then leads to overactivation of the PI3K/Akt/mTOR pathway [100]. Dysregulation of the PI3K/Akt cascade has been shown to be a major component of kidney disease [102].

\section{Conclusion}

Proper control of protein synthesis is crucial for the cell's normal functions. In all four examples of kidney disease, DN, RCC, PKD and nephritis, hyperactivation of the mTOR pathway which leads to higher rates of protein synthesis is a crucial piece of the puzzle. In many forms of kidney disease this would be expected to contribute to the chronic fibrosis that ultimately compromises kidney function. Yet, activation of stress kinases leads to the opposite response by decreasing general protein synthesis (mTOR controlled), as well as mediating upregulation of the cap-independent translation of transcripts. This switch can result in down-regulation of critical proteins while others are upregulated. Although these changes may protect cell survival in the short run, they become maladaptive and contribute to disease progression in the long run. Current research has shown disease associations with specific regulation of individual components of the systems that regulate protein translation; yet given its complexity, considerable work needs to be done to understand how different components interact to increase some proteins, decrease others and produce a significantly modified proteome that promotes disease progression.

\section{Acknowledgements}

We thank Dr. David R. Morris and Kim Hansen for critical reading of the manuscript and their helpful suggestions as well as the anonymous reviewers for their helpful criticisms. This material is the result of work supported with resources and the use of facilities at the VA Puget Sound Health Care System, Seattle, Wash., USA. The contents of this report do not represent the views of the Department of Veterans Affairs or the United States Government.

References

1 Leung AK, Sharp PA: MicroRNAs: A safeguard against turmoil? Cell 2007;130:581585.

$\checkmark 2$ Anderson P, Kedersha N: Stress granules. Curr Biol 2009;19:R397-R398.

-3 Sonenberg N, Hinnebusch AG: Regulation of translation initiation in eukaryotes: Mechanisms and biological targets. Cell 2009;136:731-745

4 Ceci M, Gaviraghi C, Gorrini C, Sala LA, Offenhauser N, Marchisio PC, Biffo S: Release of eif6 (p27bbp) from the 60s subunit allows 80 s ribosome assembly. Nature 2003;426: 579-584. 
5 Chendrimada TP, Finn KJ, Ji X, Baillat D, Gregory RI, Liebhaber SA, Pasquinelli AE, Shiekhattar R: MicroRNA silencing through risc recruitment of eif6. Nature 2007;447: 823-828.

6 Kozak M: Circumstances and mechanisms of inhibition of translation by secondary structure in eucaryotic mRNAs. Mol Cell Biol 1989;9:5134-5142.

7 Kozak M: An analysis of 5 '-noncoding sequences from 699 vertebrate messenger RNAs. Nucleic Acids Res 1987;15:81258148.

-8 Bhandari BK, Feliers D, Duraisamy S, Stewart JL, Gingras AC, Abboud HE, Choudhury GG, Sonenberg N, Kasinath BS: Insulin regulation of protein translation repressor $4 \mathrm{e}$ bp1, an eif4e-binding protein, in renal epithelial cells. Kidney Int 2001;59:866-875.

$\checkmark 9$ Mariappan MM, Shetty M, Sataranatarajan K, Choudhury GG, Kasinath BS: Glycogen synthase kinase 3beta is a novel regulator of high glucose- and high insulin-induced extracellular matrix protein synthesis in renal proximal tubular epithelial cells. J Biol Chem 2008;283:30566-30575.

10 Stoneley M, Willis AE: Cellular internal ribosome entry segments: Structures, transacting factors and regulation of gene expression. Oncogene 2004;23:3200-3207.

-11 Morris DR, Geballe AP: Upstream open reading frames as regulators of mRNA translation. Mol Cell Biol 2000;20:8635-8642.

-12 Sachs MS, Geballe AP: Downstream control of upstream open reading frames. Genes Dev 2006;20:915-921.

$\checkmark 13$ Holcik M, Sonenberg N: Translational control in stress and apoptosis. Nat Rev Mol Cell Biol 2005;6:318-327.

14 Wek RC, Jiang HY, Anthony TG: Coping with stress: Eif2 kinases and translational control. Biochem Soc Trans 2006;34:7-11.

-15 Spriggs KA, Stoneley M, Bushell M, Willis AE: Re-programming of translation following cell stress allows ires-mediated translation to predominate. Biol Cell 2008;100:2738.

-16 Yamasaki S, Anderson P: Reprogramming mRNA translation during stress. Curr Opin Cell Biol 2008;20:222-226.

-17 Kimball SR, Horetsky RL, Ron D, Jefferson LS, Harding HP: Mammalian stress granules represent sites of accumulation of stalled translation initiation complexes. Am J Physiol Cell Physiol 2003;284:C273-C284.

-18 Scott BA, Avidan MS, Crowder CM: Regulation of hypoxic death in C. elegans by the insulin/IgF receptor homolog daf-2. Science 2002;296:2388-2391.

19 Asnaghi L, Calastretti A, Bevilacqua A, D’Agnano I, Gatti G, Canti G, Delia D, Capaccioli S, Nicolin A: Bcl-2 phosphorylation and apoptosis activated by damaged microtubules require mTOR and are regulated by akt. Oncogene 2004;23:5781-5791.
20 Lamitina ST, Strange K: Transcriptional targets of daf-16 insulin signaling pathway protect C. elegans from extreme hypertonic stress. Am J Physiol Cell Physiol 2005;288: C467-C474.

21 Patel PH, Tamanoi F: Increased rheb-tor signaling enhances sensitivity of the whole organism to oxidative stress. J Cell Sci 2006; 119:4285-4292.

22 Nairn AC, Matsushita M, Nastiuk K, Horiuchi A, Mitsui K, Shimizu Y, Palfrey HC: Elongation factor-2 phosphorylation and the regulation of protein synthesis by calcium. Prog Mol Subcell Biol 2001;27:91-129.

23 Meister G: MiRNAs get an early start on translational silencing. Cell 2007;131:25-28.

24 Kloosterman WP, Plasterk RH: The diverse functions of microRNAs in animal development and disease. Dev Cell 2006;11:441450 .

25 Winter J, Jung S, Keller S, Gregory RI, Diederichs S: Many roads to maturity: MicroRNA biogenesis pathways and their regulation. Nat Cell Biol 2009; 11:228-234.

26 Thermann R, Hentze MW: Drosophila mir2 induces pseudo-polysomes and inhibits translation initiation. Nature 2007;447:875878.

27 Cannell IG, Kong YW, Bushell M: How do microRNAs regulate gene expression? Biochem Soc Trans 2008;36:1224-1231.

28 Saal S, Harvey SJ: MicroRNAs and the kidney: coming of age. Curr Opin Nephrol Hypertens 2009; 18:317-323.

29 Ha TS, Barnes JL, Stewart JL, Ko CW, Miner JH, Abrahamson DR, Sanes JR, Kasinath BS: Regulation of renal laminin in mice with type ii diabetes. J Am Soc Nephrol 1999;10: 1931-1939.

30 Kasinath BS, Mariappan MM, Sataranatarajan K, Lee MJ, Feliers D: mRNA translation: unexplored territory in renal science. J Am Soc Nephrol 2006; 17:3281-3292.

-31 Mariappan MM, Feliers D, Mummidi S, Choudhury GG, Kasinath BS: High glucose, high insulin, and their combination rapidly induce laminin-betal synthesis by regulation of mRNA translation in renal epithelial cells. Diabetes 2007;56:476-485.

-32 Sataranatarajan K, Mariappan MM, Lee MJ, Feliers D, Choudhury GG, Barnes JL, Kasinath BS: Regulation of elongation phase of mRNA translation in diabetic nephropathy: amelioration by rapamycin. Am J Pathol 2007; 171:1733-1742.

33 Inoki K: Role of TSC-mTOR pathway in diabetic nephropathy. Diabetes Res Clin Pract 2008;82(suppl 1):S59-S62.

34 Ha H, Hwang IA, Park JH, Lee HB: Role of reactive oxygen species in the pathogenesis of diabetic nephropathy. Diabetes Res Clin Pract 2008;82(suppl 1):S42-S45.

35 Lindenmeyer MT, Rastaldi MP, Ikehata M, Neusser MA, Kretzler M, Cohen CD, Schlondorff D: Proteinuria and hyperglycemia induce endoplasmic reticulum stress. J Am Soc Nephrol 2008;19:2225-2236.
36 Inagi R: Endoplasmic reticulum stress in the kidney as a novel mediator of kidney injury. Nephron Exp Nephrol 2009;112:e1-e9.

-37 Sakaguchi M, Isono M, Isshiki K, Sugimoto T, Koya D, Kashiwagi A: Inhibition of mTOR signaling with rapamycin attenuates renal hypertrophy in the early diabetic mice. Biochem Biophys Res Commun 2006;340:296301.

38 Yang Y, Wang J, Qin L, Shou Z, Zhao J, Wang $\mathrm{H}$, Chen Y, Chen J: Rapamycin prevents early steps of the development of diabetic nephropathy in rats. Am J Nephrol 2007;27: 495-502.

39 Zdychova J, Vesela J, Kazdova L, Komers R: Renal activity of akt kinase in experimental type 1 diabetes. Physiol Res 2007;57:709715.

40 Teshima-Kondo S, Kondo K, Prado-Lourenco L, Gonzalez-Herrera IG, Rokutan K, Bayard F, Arnal JF, Prats AC: Hyperglycemia upregulates translation of the fibroblast growth factor 2 mRNA in mouse aorta via internal ribosome entry site. FASEB J 2004; 18:1583-1585.

41 Gonzalez-Herrera IG, Prado-Lourenco L, Teshima-Kondo S, Kondo K, Cabon F, Arnal JF, Bayard F, Prats AC: Ires-dependent regulation of fgf-2 mRNA translation in pathophysiological conditions in the mouse. Biochem Soc Trans 2006;34:17-21.

42 Griffin E, Re A, Hamel N, Fu C, Bush H, McCaffrey T, Asch AS: A link between diabetes and atherosclerosis: glucose regulates expression of $\mathrm{cd} 36$ at the level of translation. Nat Med 2001;7:840-846.

43 Lowe WL Jr, Florkiewicz RZ, Yorek MA, Spanheimer RG, Albrecht BN: Regulation of growth factor mRNA levels in the eyes of diabetic rats. Metabolism 1995;44:1038.

44 Vasko R, Koziolek M, Ikehata M, Rastaldi MP, Jung K, Schmid H, Kretzler M, Muller GA, Strutz F: Role of basic fibroblast growth factor (fgf-2) in diabetic nephropathy and mechanisms of its induction by hyperglycemia in human renal fibroblasts. Am J Physiol Renal Physiol 2009;296:F1452-F1463.

-45 Sourris KC, Forbes JM: Interactions between advanced glycation end-products (age) and their receptors in the development and progression of diabetic nephropathy: are these receptors valid therapeutic targets. Curr Drug Targets 2009;10:42-50.

46 Shi Y, Taylor SI, Tan SL, Sonenberg N: When translation meets metabolism: multiple links to diabetes. Endocr Rev 2003;24:91-101.

-47 Taneda S, Pippin JW, Sage EH, Hudkins KL, Takeuchi Y, Couser WG, Alpers CE: Amelioration of diabetic nephropathy in SPARCnull mice. J Am Soc Nephrol 2003;14:968980 .

48 Wolf G, Schanze A, Stahl RA, Shankland SJ, Amann K: P27(kip1) knockout mice are protected from diabetic nephropathy: evidence for p27(kip1) haplotype insufficiency. Kidney Int 2005;68:1583-1589. 
-49 Petz M, Kozina D, Huber H, Siwiec T, Seipelt J, Sommergruber W, Mikulits W: The leader region of laminin b1 mRNA confers cap-independent translation. Nucleic Acids Res 2007;35:2473-2482.

- 50 Avruch J, Hara K, Lin Y, Liu M, Long X, Ortiz-Vega S, Yonezawa K: Insulin and aminoacid regulation of mTOR signaling and kinase activity through the Rheb GTPase. Oncogene 2006;25:6361-6372.

- 51 Lloberas N, Cruzado JM, Franquesa M, Herrero-Fresneda I, Torras J, Alperovich G, Rama I, Vidal A, Grinyo JM: Mammalian target of rapamycin pathway blockade slows progression of diabetic kidney disease in rats. J Am Soc Nephrol 2006;17:1395-1404.

-52 Mori H, Inoki K, Masutani K, Wakabayashi Y, Komai K, Nakagawa R, Guan KL, Yoshimura A: The mTOR pathway is highly activated in diabetic nephropathy and rapamycin has a strong therapeutic potential. Biochem Biophys Res Commun 2009;384: 471-475.

53 Wittmann S, Daniel C, Stief A, Vogelbacher R, Amann K, Hugo C: Long-term treatment of sirolimus but not cyclosporine ameliorates diabetic nephropathy in the rat. Transplantation 2009;87:1290-1299.

-54 Wang Q, Wang Y, Minto AW, Wang J, Shi Q, Li X, Quigg RJ: MicroRNA-377 is up-regulated and can lead to increased fibronectin production in diabetic nephropathy. FASEB J 2008;22:4126-4135.

55 Kato M, Zhang J, Wang M, Lanting L, Yuan H, Rossi JJ, Natarajan R: MicroRNA-192 in diabetic kidney glomeruli and its function in TGF-beta-induced collagen expression via inhibition of e-box repressors. Proc Natl Acad Sci USA 2007;104:3432-3437.

56 Abrass CK, Spicer D, Berfield AK, St John PL, Abrahamson DR: Diabetes induces changes in glomerular development and laminin-beta 2 (s-laminin) expression. Am J Pathol 1997;151:1131-1140.

57 Schaeffer V, Hansen KM, Morris DR, Abrass CK: Reductions in laminin \{beta\} 2 mRNA translation are responsible for impaired IgFbp-5-mediated mesangial cell migration in the presence of high glucose. Am J Physiol Renal Physiol 2009;in press.

- 58 Pierson M, Cordier J, Hervouuet F, Rauber G: An unusual congenital and familial congenital malformative combination involving the eye and kidney. J Genet Hum 1963;12: 184-213.

59 Zenker M, Aigner T, Wendler O, Tralau T, Muntefering H, Fenski R, Pitz S, Schumacher V, Royer-Pokora B, Wuhl E, Cochat P, Bouvier R, Kraus C, Mark K, Madlon H, Dotsch J, Rascher W, Maruniak-Chudek I, Lennert T, Neumann LM, Reis A: Human laminin beta2 deficiency causes congenital nephrosis with mesangial sclerosis and distinct eye abnormalities. Hum Mol Genet 2004;13:2625-2632.
60 Zenker M, Tralau T, Lennert T, Pitz S, Mark K, Madlon H, Dotsch J, Reis A, Muntefering H, Neumann LM: Congenital nephrosis, mesangial sclerosis, and distinct eye abnormalities with microcoria: an autosomal recessive syndrome. Am J Med Genet [A] 2004; 130A:138-145.

61 Zenker M, Pierson M, Jonveaux P, Reis A: Demonstration of two novel lamb2 mutations in the original Pierson syndrome family reported 42 years ago. Am J Med Genet A 2005;138:73-74.

62 Jarad G, Cunningham J, Shaw AS, Miner JH: Proteinuria precedes podocyte abnormalities in lamb2-/- mice, implicating the glomerular basement membrane as an albumin barrier. J Clin Invest 2006;116:2272-2279.

63 Kato M, Arce L, Natarajan R: MicroRNAs and their role in progressive kidney diseases. Clin J Am Soc Nephrol 2009;4:1255-1266.

64 Kato M, Putta S, Wang M, Yuan H, Lanting L, Nair I, Gunn A, Nakagawa Y, Shimano H, Todorov I, Rossi JJ, Natarajan R: TGF-beta activates akt kinase through a microRNAdependent amplifying circuit targeting PTEN. Nat Cell Biol 2009;11:881-889.

$\checkmark 65$ Abrass CK, Peterson CV, Raugi GJ: Phenotypic expression of collagen types in mesangial matrix of diabetic and nondiabetic rats. Diabetes 1988;37:1695-1702.

66 Abrass CK, Spicer D, Raugi GJ: Insulin induces a change in extracellular matrix glycoproteins synthesized by rat mesangial cells in culture. Kidney Int 1994;46:613-620.

67 Abrass CK: Diabetic nephropathy: mechanisms of mesangial matrix expansion. West J Med 1995;162:318-321.

68 Abrass CK, Spicer D, Raugi GJ: Induction of nodular sclerosis by insulin in rat mesangial cells in vitro: studies of collagen. Kidney Int 1995;47:25-37.

-69 Sivan G, Elroy-Stein O: Regulation of mRNA translation during cellular division. Cell Cycle 2008;7:741-744.

70 Robb VA, Karbowniczek M, Klein-Szanto AJ, Henske EP: Activation of the mTOR signaling pathway in renal clear cell carcinoma. J Urol 2007;177:346-352.

71 Yilmaz M, Christofori G: Emt, the cytoskeleton, and cancer cell invasion. Cancer Metastasis Rev 2009;28:15-33.

72 Raught B, Gingras AC: Eif4e activity is regulated at multiple levels. Int J Biochem Cell Biol 1999;31:43-57.

73 Laughner E, Taghavi P, Chiles K, Mahon PC, Semenza GL: Her2 (neu) signaling increases the rate of hypoxia-inducible factor lalpha (HIF-lalpha) synthesis: novel mechanism for HIF-1-mediated vascular endothelial growth factor expression. Mol Cell Biol 2001; 21:3995-4004.

74 Sola-Villa D, Camacho M, Sola R, Soler M, Diaz JM, Vila L: IL-1beta induces VEGF, independently of PGE2 induction, mainly through the PI3-K/mTOR pathway in renal mesangial cells. Kidney Int 2006;70:19351941.
5 Hudes GR: Targeting mTOR in renal cell carcinoma. Cancer 2009;115:2313-2320.

76 Shor B, Zhang WG, Toral-Barza L, Lucas J, Abraham RT, Gibbons JJ, Yu K: A new pharmacologic action of CCI-779 involves FKBP12-independent inhibition of mTOR kinase activity and profound repression of global protein synthesis. Cancer Res 2008; 68:2934-2943.

77 Woodard J, Sassano A, Hay N, Platanias LC: Statin-dependent suppression of the akt/ mammalian target of rapamycin signaling cascade and programmed cell death 4 upregulation in renal cell carcinoma. Clin Cancer Res 2008;14:4640-4649.

-78 Nakada C, Matsuura K, Tsukamoto Y, Tanigawa M, Yoshimoto T, Narimatsu T, Nguyen LT, Hijiya N, Uchida T, Sato F, Mimata H, Seto M, Moriyama M: Genome-wide microRNA expression profiling in renal cell carcinoma: significant down-regulation of mir-141 and mir-200c. J Pathol 2008;216: 418-427.

77 Heicappell R: Cadherins in renal cell carcinoma. Anticancer Res 1999;19:1501-1504.

80 Cavallaro U, Christofori G: Cell adhesion and signalling by cadherins and Ig-cams in cancer. Nat Rev Cancer 2004;4:118-132.

81 Dutta KK, Zhong Y, Liu YT, Yamada T, Akatsuka S, Hu Q, Yoshihara M, Ohara H, Takehashi M, Shinohara T, Masutani H, Onuki J, Toyokuni S: Association of microRNA-34a overexpression with proliferation is cell type-dependent. Cancer Sci 2007;98:18451852.

82 Wilson PD: Polycystic kidney disease: new understanding in the pathogenesis. Int J Biochem Cell Biol 2004;36:1868-1873.

83 Yoder BK, Mulroy S, Eustace H, Boucher C, Sandford R: Molecular pathogenesis of autosomal dominant polycystic kidney disease. Expert Rev Mol Med 2006;8:1-22.

84 Shillingford JM, Murcia NS, Larson CH, Low SH, Hedgepeth R, Brown N, Flask CA, Novick AC, Goldfarb DA, Kramer-Zucker A, Walz G, Piontek KB, Germino GG, Weimbs $\mathrm{T}$ : The mTOR pathway is regulated by polycystin-1, and its inhibition reverses renal cystogenesis in polycystic kidney disease. Proc Natl Acad Sci USA 2006;103:54665471.

85 Zheng R, Wang L, Fan J, Zhou Q: Inhibition of PKHD1 may cause S-phase entry via mTOR signaling pathway. Cell Biol Int 2009; 33:926-933

-86 Tao Y, Kim J, Schrier RW, Edelstein CL: Rapamycin markedly slows disease progression in a rat model of polycystic kidney disease. J Am Soc Nephrol 2005;16:46-51.

87 Wahl PR, Serra AL, Le Hir M, Molle KD, Hall MN, Wuthrich RP: Inhibition of mTOR with sirolimus slows disease progression in han:Sprd rats with autosomal dominant polycystickidney disease (ADPKD). Nephrol Dial Transplant 2006;21:598-604. 
-88 Zafar I, Belibi FA, He Z, Edelstein CL: Longterm rapamycin therapy in the han:Sprd rat model of polycystic kidney disease (PKD). Nephrol Dial Transplant 2009;24:23492353.

-89 Liang G, Yang J, Wang Z, Li Q, Tang Y, Chen $\mathrm{XZ}$ : Polycystin-2 down-regulates cell proliferation via promoting perk-dependent phosphorylation of eif2alpha. Hum Mol Genet 2008; 17:3254-3262.

90 Lee SO, Masyuk T, Splinter P, Banales JM, Masyuk A, Stroope A, Larusso N: MicroRNA15a modulates expression of the cellcycle regulator CDC25a and affects hepatic cystogenesis in a rat model of polycystic kidney disease. J Clin Invest 2008;118:37143724.

-91 Pandey P, Brors B, Srivastava PK, Bott A, Boehn SN, Groene HJ, Gretz N: Microarraybased approach identifies microRNAs and their target functional patterns in polycystic kidney disease. BMC Genomics 2008;9:624.

-92 Reddy PS, Legault HM, Sypek JP, Collins MJ, Goad E, Goldman SJ, Liu W, Murray S, Dorner AJ, O’Toole M: Mapping similarities in mTOR pathway perturbations in mouse lupus nephritis models and human lupus nephritis. Arthritis Res Ther 2008;10:R127.

$\checkmark 93$ Wittmann S, Daniel C, Braun A, Vogelbacher R, Shimizu F, Kawachi H, Hugo C: The mTOR inhibitor everolimus attenuates the time course of chronic anti-thyl nephritis in the rat. Nephron Exp Nephrol 2008;108: e45-e56.

94 Kramer S, Wang-Rosenke Y, Scholl V, Binder E, Loof T, Khadzhynov D, Kawachi H, Shimizu F, Diekmann F, Budde K, Neumayer $\mathrm{HH}$, Peters $\mathrm{H}$ : Low-dose mTOR inhibition by rapamycin attenuates progression in antithyl-induced chronic glomerulosclerosis of the rat. Am J Physiol Renal Physiol 2008;294: F440-F449.

$\checkmark 95$ Bijian K, Cybulsky AV: Stress proteins in glomerular epithelial cell injury. Contrib Nephrol. Basel, Karger, 2005, vol 148, pp 820.
\$6 Cybulsky AV, Takano T, Papillon J, Bijian $\mathrm{K}$ : Role of the endoplasmic reticulum unfolded protein response in glomerular epithelial cell injury. J Biol Chem 2005;280: 24396-24403.

$\checkmark 97$ Cybulsky AV, Takano T, Papillon J, Khadir A, Liu J, Peng H: Complement c5b-9 membrane attack complex increases expression of endoplasmic reticulum stress proteins in glomerular epithelial cells. J Biol Chem 2002;277:41342-41351.

98 Inagi R, Kumagai T, Nishi H, Kawakami T, Miyata T, Fujita T, Nangaku M: Preconditioning with endoplasmic reticulum stress ameliorates mesangioproliferative glomerulonephritis. J Am Soc Nephrol 2008;19: 915-922.

$\checkmark 99$ Pauley KM, Cha S, Chan EK: MicroRNA in autoimmunity and autoimmune diseases. Autoimmun 2009;32:189-194.

100 Xiao C, Srinivasan L, Calado DP, Patterson $\mathrm{HC}$, Zhang B, Wang J, Henderson JM, Kutok JL, Rajewsky K: Lymphoproliferative disease and autoimmunity in mice with increased mir-17-92 expression in lymphocytes. Nat Immunol 2008;9:405-414.

101 Brock M, Trenkmann M, Gay RE, Michel BA, Gay S, Fischler M, Ulrich S, Speich R, Huber LC: Interleukin-6 modulates the expression of the bone morphogenic protein receptor type II through a novel stat3-microRNA cluster 17/92 pathway. Circ Res 2009;104:1184-1191.

102 Peairs A, Radjavi A, Davis S, Li L, Ahmed A, Giri S, Reilly CM: Activation of ampk inhibits inflammation in $\mathrm{mrl} / \mathrm{lpr}$ mouse mesangial cells. Clin Exp Immunol 2009; 156:542-551.

103 Sancak Y, Thoreen CC, Peterson TR, Lindquist RA, Kang SA, Spooner E, Carr SA, Sabatini DM: Pras40 is an insulin-regulated inhibitor of the mTORC1 protein $\mathrm{ki}$ nase. Mol Cell 2007;25:903-915.
104 Sarbassov DD, Ali SM, Sengupta S, Sheen JH, Hsu PP, Bagley AF, Markhard AL, Sabatini DM: Prolonged rapamycin treatment inhibits mTORC2 assembly and akt/pkb. Mol Cell 2006;22:159-168.

105 Hay N, Sonenberg N: Upstream and downstream of mTOR. Genes Dev 2004;18:19261945.

106 Wullschleger S, Loewith R, Hall MN: TOR signaling in growth and metabolism. Cell 2006;124:471-484.

107 Tee AR, Blenis J: mTOR, translational control and human disease. Semin Cell Dev Biol 2005; 16:29-37.

108 Holz MK, Blenis J: Identification of s6 kinase 1 as a novel mammalian target of rapamycin (mTOR)-phosphorylating kinase. J Biol Chem 2005;280:26089-26093.

109 Stolovich M, Tang H, Hornstein E, Levy G, Cohen R, Bae SS, Birnbaum MJ, Meyuhas $\mathrm{O}$ : Transduction of growth or mitogenic signals into translational activation of top mRNAs is fully reliant on the phosphatidylinositol 3-kinase-mediated pathway but requires neither s6k1 nor rps6 phosphorylation. Mol Cell Biol 2002;22:8101-8113.

110 Pende M, Um SH, Mieulet V, Sticker M, Goss VL, Mestan J, Mueller M, Fumagalli S, Kozma SC, Thomas G: S6k1(-/-)/s6k2(/-) mice exhibit perinatal lethality and rapamycin-sensitive 5 '-terminal oligopyrimidine mRNA translation and reveal a mitogen-activated protein kinase-dependent s6 kinase pathway. Mol Cell Biol 2004; 24:3112-3124.

111 Gingras AC, Raught B, Sonenberg N: mTOR signaling to translation. Curr Top Microbiol Immunol 2004;279:169-197.

112 Asnaghi L, Bruno P, Priulla M, Nicolin A: mTOR: A protein kinase switching between life and death. Pharmacol Res 2004;50: 545-549.

113 Lankat-Buttgereit B, Goke R: The tumour suppressor pdcd4: recent advances in the elucidation of function and regulation. Biol Cell 2009;101:309-317. 